\title{
Liquid Gastric Emptying as an Adjunct to Hepatobiliary Scintigraphy When Oral Corn Oil Is Used as a Cholecystagogue for Determining Gallbladder Emptying
}

\author{
James A. Ponto \\ Department of Radiology, University of Iowa Hospitals and Clinics, and University of Iowa College of Pharmacy, Iowa City, Iowa
}

During times of sincalide shortage, a fatty meal can be used to stimulate gallbladder contraction during hepatobiliary scintigraphy. However, if a patient has an abnormal gallbladder ejection fraction (GBEF), is the cause chronic cholecystitis or is it inadequate cholecystokinin stimulation due to poor gastric emptying? Hence, during the 2014 sincalide shortage, simultaneous liquid gastric emptying using $99 \mathrm{~m}$ Tc-sulfur colloid along with corn oil emulsion was initiated as routine practice in patients evaluated for GBEF. The objective of this study was to retrospectively assess the time course of gastric emptying in these patients, especially with regard to whether delayed gastric emptying may be a factor in some patients with a poor GBEF. Methods: My institution's clinical imaging procedure during the 2014 sincalide shortage consisted of routine 99mTc-mebrofenin hepatobiliary scintigraphy followed by corn oil emulsion and 99mTc-sulfur colloid orally. Dynamic imaging with regions of interest encompassing the gallbladder and the stomach allowed determination of GBEF and gastric emptying. For this study, the imaging records for 53 consecutive patients undergoing this clinical procedure were reviewed. The time for half gastric emptying, along with percentage gastric emptying at the end of imaging, was evaluated in relationship to GBEF. Results: Seventeen patients had a normal GBEF (74\% $\pm 14 \%)$ and satisfactory gastric emptying (31 \pm 21 min for half emptying, $75 \% \pm 14 \%$ emptying at end of imaging); 17 patients had a normal GBEF $(77 \% \pm 17 \%)$ despite unsatisfactory gastric emptying (only $30 \% \pm 14 \%$ emptying at end of imaging); 5 patients had an abnormal GBEF (19\% $\pm 9 \%)$ and satisfactory gastric emptying (26 \pm 19 min for half emptying, $82 \% \pm 14 \%$ emptying at end of imaging), supporting a diagnosis of chronic cholecystitis; 11 patients had an abnormal GBEF $(26 \% \pm 9 \%)$ but also unsatisfactory gastric emptying (only $26 \% \pm 13 \%$ emptying at end of imaging), which did offer additional support for a diagnosis of chronic cholecystitis; and 3 patients had a borderline GBEF $(40 \% \pm 2 \%)$ with satisfactory gastric emptying $(59 \% \pm 6 \%$ emptying at end of imaging). Conclusion: Simultaneous liquid gastric emptying can provide additional information in the interpretation of GBEF when a fatty meal is used as an oral cholecystagogue, especially to help differentiate chronic cholecystitis from inadequate cholecystokinin stimulation due to poor gastric emptying.

Received Jan. 9, 2015; revision accepted Mar. 16, 2015.

For correspondence or reprints contact: James A. Ponto, Nuclear Medicine 3832 JPP, University of lowa Hospitals and Clinics, 200 Hawkins Dr., lowa City, IA 52242.

E-mail: james-ponto@uiowa.edu

Published online Apr. 9, 2015.

COPYRIGHT (C) 2015 by the Society of Nuclear Medicine and Molecular Imaging, Inc.
Key Words: gallbladder ejection fraction; chronic cholecystitis; corn oil emulsion; hepatobiliary scintigraphy; ${ }^{99 m T c-m e b r o f e n i n ~}$

J Nucl Med Technol 2015; 43:117-121

DOI: 10.2967/jnmt.115.153866

O incalide, a synthetic octapeptide of the $C$ terminal (active portion) of the hormone cholecystokinin, is a Food and Drug Administration-approved drug product indicated to stimulate contraction of the gallbladder as assessed by various diagnostic imaging methods (1). It is widely used to evaluate gallbladder contraction and emptying (gallbladder ejection fraction $[\mathrm{GBEF}])$ during hepatobiliary scintigraphy (2-5). During times of sincalide shortage, alternative approaches are needed. Although some have used sincalide preparations obtained from compounding pharmacies, caution has been urged $(6,7)$. Alternatively, oral fatty meals can be used to stimulate small-bowel release of endogenous cholecystokinin (7). During a previous shortage of sincalide, my institution investigated the use of an oral corn oil emulsion as a simple cholecystagogue (8). The corn oil emulsion was compounded by the hospital pharmacy based on the formula for the historically marketed Lipomul, a commercial emulsified corn oil product from Upjohn, which was discontinued in $1979(8,9)$.

Although oral fatty meals may be useful for confirming normal GBEF, abnormal GBEF remains problematic for interpretation: is the cause chronic cholecystitis or is it inadequate stimulation by endogenous cholecystokinin due to poor gastric emptying of fat into the small bowel and thus delayed release of endogenous cholecystokinin? Hence, when corn oil emulsion was used as an oral cholecystagogue during the 2014 shortage of sincalide, my institution initiated as routine practice the performance of simultaneous liquid gastric emptying using ${ }^{99 \mathrm{~m}} \mathrm{Tc}$-sulfur colloid along with the corn oil emulsion. Dynamic imaging with regions of interest encompassing the gallbladder and the stomach allowed the determination of GBEF and gastric emptying.

The objective of this study was to retrospectively assess the time course of gastric emptying in patients who had received corn oil as an oral cholecystagogue to stimulate 
gallbladder contraction, especially with regard to whether delayed gastric emptying may be a factor in some patients with a poor GBEF.

\section{MATERIALS AND METHODS}

For this study, the imaging records for 53 consecutive patients who had received oral corn oil emulsion and ${ }^{99 \mathrm{~m}} \mathrm{Tc}$-sulfur colloid during hepatobiliary imaging procedures for their clinical care were retrospectively reviewed. In addition to images, these records included time-activity curves for gallbladder emptying and for gastric emptying based on regions of interest encompassing the gallbladder and the stomach, respectively.

Briefly, my institution's clinical imaging procedure during the 2014 shortage of sincalide consisted of routine hepatobiliary scintigraphy after injection of $185 \mathrm{MBq}(5 \mathrm{mCi})$ of ${ }^{99 \mathrm{~m}} \mathrm{Tc}-$ mebrofenin. After about 45-60 min, the nuclear medicine physician reviewed the images and determined whether to proceed with evaluation of gallbladder emptying. If so, $30 \mathrm{~mL}(20 \mathrm{~g})$ of corn oil emulsion and 18.5 MBq $(0.5 \mathrm{mCi})$ of ${ }^{99 \mathrm{~m}} \mathrm{Tc}$-sulfur colloid were administered orally, immediately followed by $90 \mathrm{~mL}$ of water. Dynamic imaging was then performed in the $20^{\circ}$ left anterior oblique position for an additional 60-90 min, as directed by the nuclear medicine physician. Regions of interest placed around the gallbladder and the stomach allowed the creation of time-activity curves that showed gallbladder emptying and gastric emptying, respectively. GBEF was calculated from the gallbladder time-activity curve as follows:

$$
\begin{aligned}
\mathrm{GBEF}= & {[(\text { maximum activity })} \\
& -(\text { minimum activity })] /(\text { maximum activity }) .
\end{aligned}
$$

The medical literature suggests that $10 \mathrm{~g}$ of fat delivered to the proximal small bowel, which causes release of endogenous cholecystokinin, is generally needed to produce maximal gallbladder contraction $(5,10)$. The administered dose of corn oil contained $20 \mathrm{~g}$; half this administered dose is $10 \mathrm{~g}$ of corn oil. Hence, as appropriate parameters for evaluation in relationship to GBEF, I chose the time for half gastric emptying (i.e., the time for half the administered dose of $20 \mathrm{~g}$ of corn oil to pass from the stomach into the intestine), along with percentage gastric emptying at the end of imaging. I chose greater than 50\% gastric emptying during imaging as indicating satisfactory gastric emptying (i.e., providing delivery of $>10 \mathrm{~g}$ of corn oil into the small bowel). Classification of GBEF as normal, abnormal, or borderline in these patients was accepted as stated in the interpreting physician's dictated report.

The Institutional Review Board reviewed this proposed retrospective study and deemed it to be a quality control assessment related to performance of a clinical imaging procedure, which did not require approval by the Institutional Review Board or written informed consent.

\section{RESULTS}

Values of GBEF in these patients varied widely, ranging from $6 \%$ to $96 \%$. The rates of gastric emptying in these patients also varied widely, with times for half gastric emptying ranging from $4 \mathrm{~min}$ to more than $90 \mathrm{~min}$. Similarly, the percentage gastric emptying at the end of imaging varied widely, ranging from $7 \%$ to $95 \%$. Retrospectively, 50 of the 53 patients fell into 1 of 4 distinct groups: normal GBEF and satisfactory gastric emptying; normal GBEF despite unsatisfactory gastric emptying; abnormal GBEF and satisfactory gastric emptying; and abnormal GBEF with unsatisfactory gastric emptying. Three patients had borderline GBEF and satisfactory gastric emptying. Data for these groups are summarized in Table 1.

Representative imaging results for 1 patient from each of the 4 groups, as copied from their medical imaging records, are presented in Figures 1-4.

The oral corn oil emulsion was well tolerated in these patients, with no reports of adverse effects.

\section{DISCUSSION}

Normal GBEF generally excludes a diagnosis of chronic cholecystitis, whereas an abnormal GBEF is highly suggestive of chronic cholecystitis. However, when an oral fatty meal is used as a cholecystagogue, interpretation of abnormal GBEF as being chronic cholecystitis is problematic because the gallbladder could have been inadequately stimulated during the imaging procedure if there was poor gastric emptying of the fatty meal. Hence, simultaneous

TABLE 1

Results for GBEF and Gastric Emptying

\begin{tabular}{ccccc}
\hline \multicolumn{1}{c}{ Group } & Patients $(n)$ & GBEF (\%) & $\begin{array}{c}\text { Time for half gastric } \\
\text { emptying (min) }\end{array}$ & $\begin{array}{c}\text { Gastric emptying at end } \\
\text { of imaging (\%) }\end{array}$ \\
\hline $\begin{array}{c}\text { Normal GBEF; satisfactory gastric } \\
\text { emptying }\end{array}$ & 17 & $74 \pm 14$ & $31 \pm 21$ & $75 \pm 14$ \\
$\quad \begin{array}{c}\text { Normal GBEF; unsatisfactory gastric } \\
\text { emptying }\end{array}$ & 17 & $77 \pm 17$ & $>60-90^{*}$ & $30 \pm 14$ \\
$\begin{array}{c}\text { Abnormal GBEF; satisfactory gastric } \\
\text { emptying }\end{array}$ & 5 & $19 \pm 9$ & $26 \pm 19$ & $82 \pm 14$ \\
$\begin{array}{c}\text { Abnormal GBEF; unsatisfactory gastric } \\
\text { emptying }\end{array}$ & 11 & $26 \pm 9$ & $>60-90^{*}$ & $26 \pm 13$ \\
$\begin{array}{c}\text { Borderline GBEF; satisfactory gastric } \\
\text { emptying }\end{array}$ & 3 & $40 \pm 2$ & $34 \pm 44$ & $59 \pm 6$ \\
\hline
\end{tabular}

*Half gastric emptying not reached by end of imaging.

Data are mean \pm SD. 

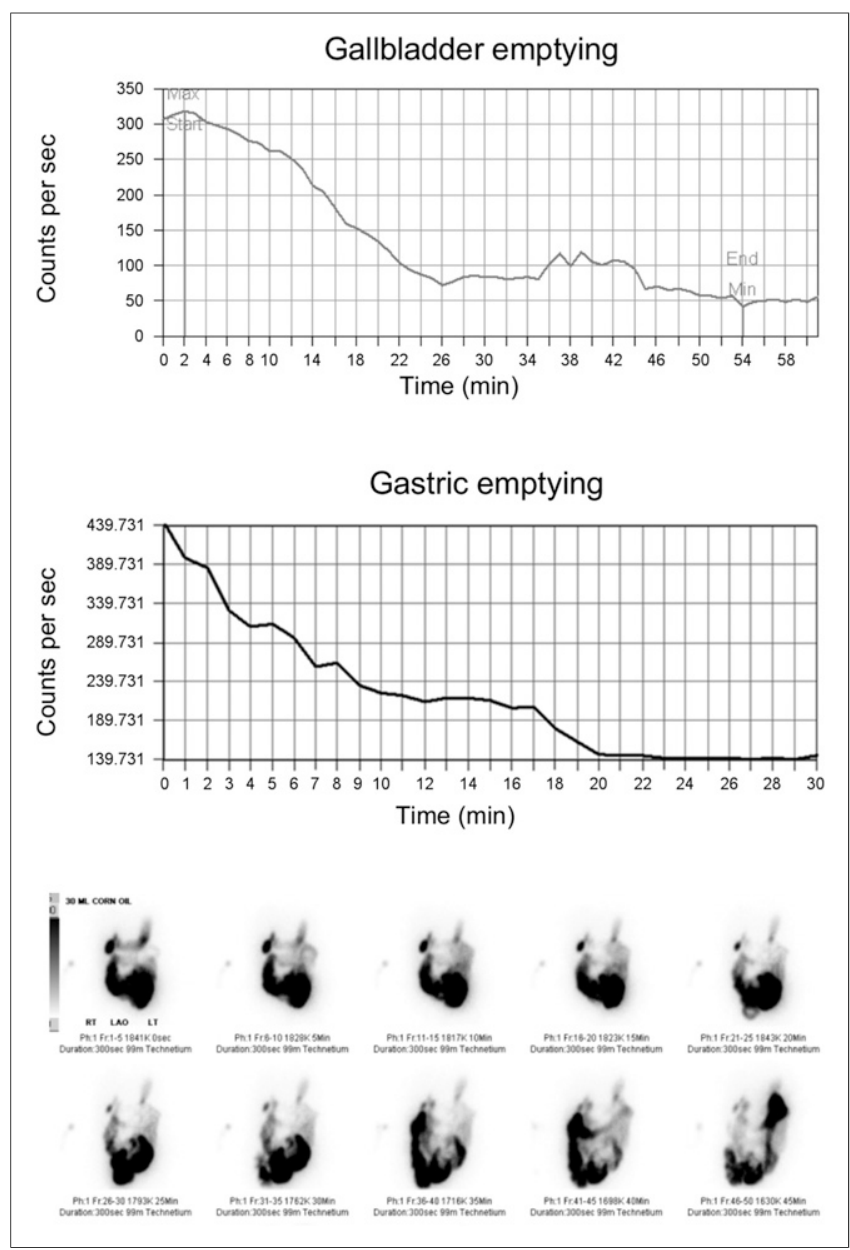

FIGURE 1. Time-activity curves for gallbladder emptying, gastric emptying, and biliary images after corn oil emulsion for patient with normal GBEF (87\%) and satisfactory gastric emptying.

liquid gastric emptying using ${ }^{99 \mathrm{~m}} \mathrm{Tc}$-sulfur colloid can potentially aid in interpretation for this group.

A minority of patients (16/53) exhibited abnormal GBEF, which is suggestive of chronic cholecystitis. Of these 16 patients, 5 had satisfactory gastric emptying, which strongly supports the diagnosis of chronic cholecystis. The other 11 patients had unsatisfactory gastric emptying, which failed to additionally support an interpretation of chronic cholecystitis for the abnormal GBEF, because the question remains of whether the abnormal GBEF was truly due to chronic cholecystitis or was due to inadequate cholecystokinin stimulation. Although simultaneous gastric emptying had limited usefulness in this patient sample overall, it did in fact help support the diagnosis of chronic cholecystitis in a small group of patients.

The normal value for GBEF is difficult to establish because of its wide variation. Reported normal values for GBEF using various doses of sincalide administered over various infusion times have ranged from $30 \%$ to $65 \%(3,4)$. Reported normal values for GBEF from fatty meals are also quite variable: more than $20 \%-34 \%$ for $30 \mathrm{~mL}$ of corn oil emulsion
(20 g fat) (8), $24 \%$ or more for $237 \mathrm{~mL}(8 \mathrm{oz}) / 70 \mathrm{~kg}$ of halfand-half (24 $\mathrm{g}$ of fat) (11), 33\% or more for $8 \mathrm{oz}$ of Ensure Plus (11.4 g of fat; Abbott Laboratories) (12), $44 \%-51 \%$ or more for $250 \mathrm{~mL}$ of milk (approximately $8 \mathrm{~g}$ of fat) (13), and $49 \%$ or more for $89 \mathrm{~mL}(3 \mathrm{oz})$ of whipping cream (30 g of fat) (14). Because this study collected GBEF data that were determined and interpreted as part of a routine clinical procedure, individual physicians were free to use whatever normal value they felt was most appropriate. Hence, for this study, classification of GBEF as normal, abnormal, or borderline in these patients was accepted as stated in the interpreting physician's dictated report.

This study was not intended to evaluate the efficacy of corn oil emulsion for stimulating gallbladder contraction. Nor was it intended to determine the sensitivity and specificity of this clinical procedure. Rather, the focus of this study was limited to the evaluation of gastric emptying as an aid to physicians in interpreting GBEF when using a fatty meal as an oral cholecystagogue. Hence, a limitation of this study was that the physician's interpretation or diagnosis was not confirmed by patient follow-up or outcome.

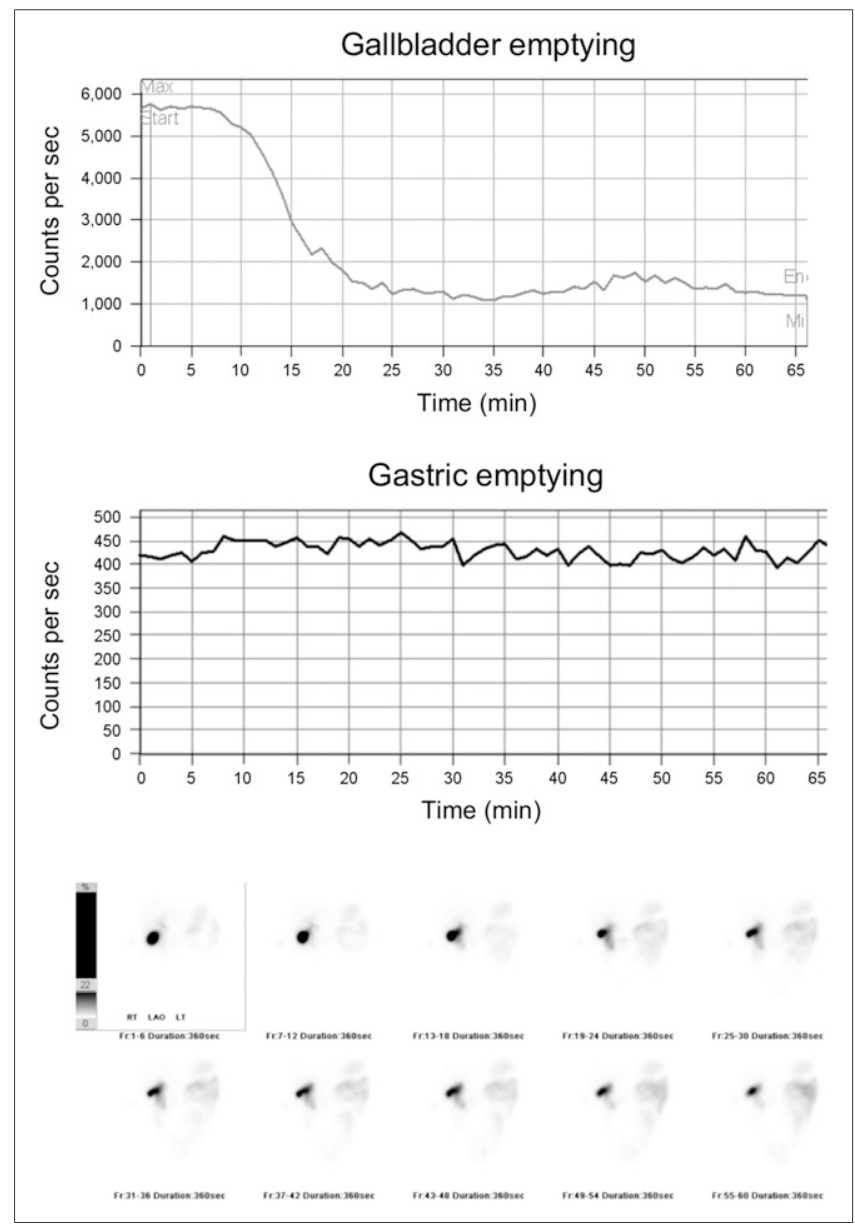

FIGURE 2. Time-activity curves for gallbladder emptying, gastric emptying, and biliary images after corn oil emulsion for patient with normal GBEF (79\%) despite unsatisfactory gastric emptying. 


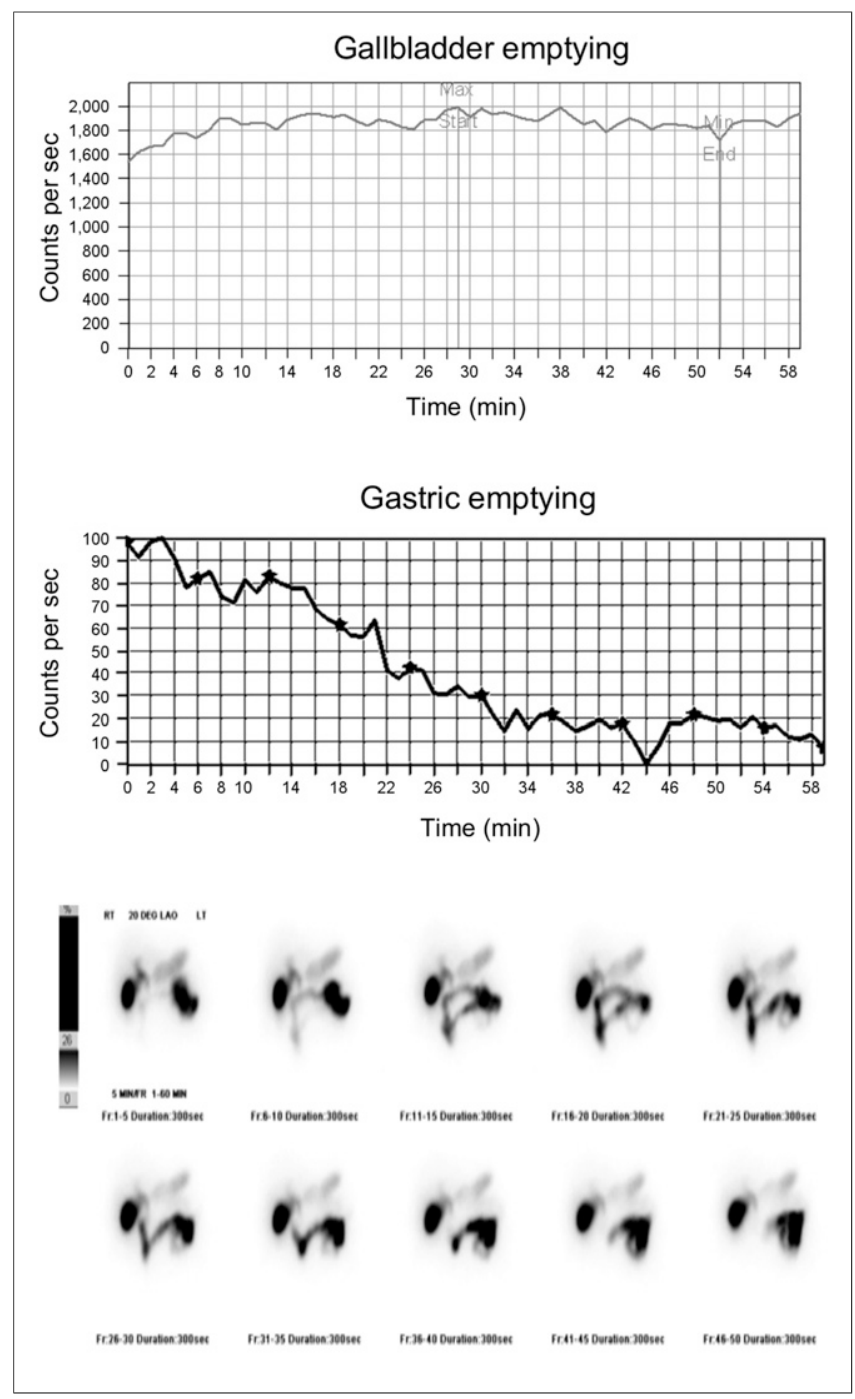

FIGURE 3. Time-activity curves for gallbladder emptying, gastric emptying, and biliary images after corn oil emulsion for patient with abnormal GBEF (14\%) and satisfactory gastric emptying, highly suggestive of chronic cholecystitis.

Because this study used retrospective data gathered from routine clinical procedures, a further limitation was the lack of an established normal value for interpretation of GBEF. For example, for 3 patients, the interpreting physician dictated that the GBEF was borderline. Despite this limitation, most GBEF values were clearly normal or clearly abnormal regardless of whatever normal value was used by the interpreting physician (Table 1).

It is interesting and puzzling that 17 patients had a normal GBEF despite unsatisfactory gastric emptying. The reason was not sought as part of this study and is not known. One reasonable explanation is that a loop of bowel may have overlapped the stomach region of interest and thereby falsely elevated the counts in that region of interest. Another potential explanation is that gallbladder emptying may be induced by the delivery of substantially less than $10 \mathrm{~g}$ of fat into the proximal small bowel. For example, a GBEF greater than $44 \%-51 \%$ has been reported when $250 \mathrm{~mL}$ of whole milk (13) is used, which contains a total of only about $8 \mathrm{~g}$ of fat. Also, $4 \mathrm{~g}$ of fat has been shown to induce substantial, albeit submaximal, gallbladder contraction (10). Yet another potential explanation could be the occurrence of intestinalgastric reflux, whereby corn oil and ${ }^{99 \mathrm{~m}} \mathrm{Tc}$-sulfur colloid are delivered into the intestine but some ${ }^{99 \mathrm{~m}} \mathrm{Tc}$-sulfur colloid or ${ }^{99 \mathrm{~m}} \mathrm{Tc}$-mebrofenin is refluxed back up into the stomach. Intestinal-gastric reflux was noted by the interpreting physician in one patient's imaging report. Regardless of the reason, this issue is of little concern to the interpreting physician because a normal GBEF generally rules out chronic cholecystitis.

\section{CONCLUSION}

Simultaneous gastric emptying using ${ }^{99 \mathrm{~m}} \mathrm{Tc}$-sulfur colloid can provide additional information in the evaluation

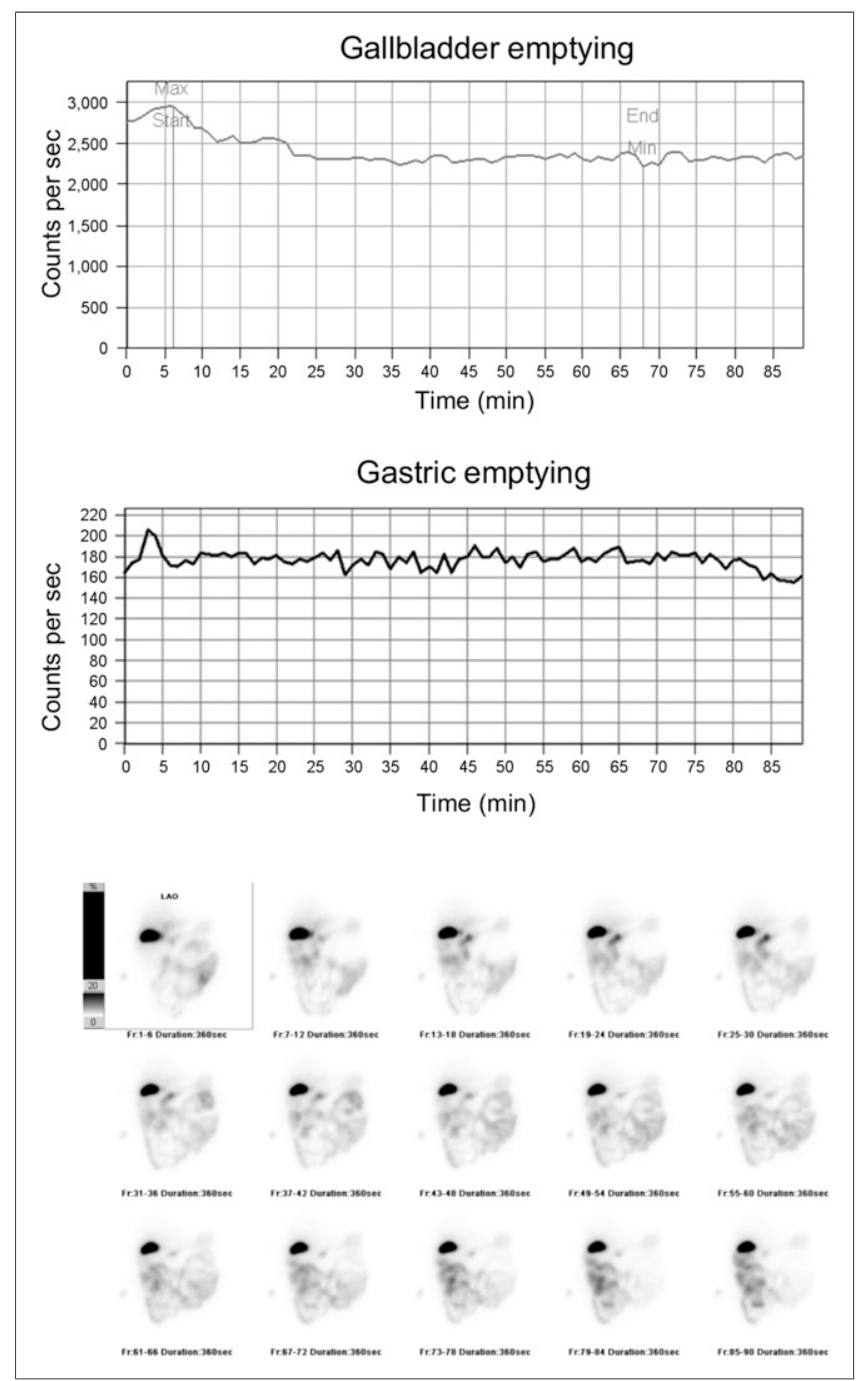

FIGURE 4. Time-activity curves for gallbladder emptying, gastric emptying, and biliary images after corn oil emulsion for patient with abnormal GBEF (25\%) and unsatisfactory gastric emptying, which may be chronic cholecystitis but may also be inadequate cholecystokinin stimulation due to poor gastric emptying. 
of GBEF when a fatty meal is used as an oral cholecystagogue during ${ }^{99 \mathrm{~m}} \mathrm{Tc}$-mebrofenin hepatobiliary scintigraphy. This technique may be especially useful in patients with an abnormal GBEF to help differentiate chronic cholecystitis from inadequate cholecystokinin stimulation due to poor gastric emptying.

\section{DISCLOSURE}

No potential conflict of interest relevant to this article was reported.

\section{ACKNOWLEDGMENT}

Michael M. Graham, PhD, MD, is acknowledged for helpful discussions and for establishing simultaneous liquid gastric emptying as routine practice for these patients in the University of Iowa Hospitals and Clinics.

\section{REFERENCES}

1. Kinevac [package insert]. Princeton, NJ: Bracco Diagnostics; May 2011.

2. Tulchinsky M, Ciak BW, Delbeke D, et al. SNM practice guideline for hepatobiliary scintigraphy 4.0. J Nucl Med. 2010;38:210-218.
3. Ziessman HA. Functional hepatobiliary disease: chronic acalculous gallbladder and chronic acalculous biliary disease. Semin Nucl Med. 2006;36:119-132.

4. Ziessman HA, Tulchinsky M, Lavely WC, et al. Sincalide-stimulated cholescintigraphy: a multi-center investigation to determine optimal infusion methodology and gallbladder ejection fraction normal values. J Nucl Med. 2010;51:277-281.

5. Ziessman HA. Hepatobiliary scintigraphy in 2014. J Nucl Med. 2014;55:967975 .

6. Norenberg JP, Ponto JA, Petry NA, Wittstrom KM. Prescriber beware: it is ill advised to administer compounded sincalide. J Nucl Med. 2013;54(11):23N$24 \mathrm{~N}$.

7. Ziessman H, Petry NA. Sincalide is temporarily unavailable-again. J Nucl Med. 2013;54(8):17N.

8. Bartel TB, Juweid ME, Ponto JA, Graham MM. Corn oil emulsion: a simple cholecystagogue for diagnosis of chronic acalculous cholecystitis. J Nucl Med. 2005;46:67-74.

9. Lipomul from Upjohn: product ID 2618788. In: Micromedex Healthcare Series. Vol 11. Greenwood Village, CO: Thomson; 2002.

10. Stone BG, Ansel HJ, Peterson FJ, et al. Gallbladder emptying stimuli in obese and normal weight subjects. Hepatology. 1992;15:795-798.

11. Krishnamurthy GT, Brown PH. Comparison of fatty meal and intravenous cholecystokinin infusion for gallbladder ejection fraction. J Nucl Med. 2002;43:16031610 .

12. Ziessman HA, Jones DA, Muenz LR, et al. Cholecystokinin cholescintigraphy: methodology and normal values using a lactose-free fatty meal food supplement. J Nucl Med. 2003;44:1263-1266.

13. Xynos E, Pechlivanides G, Zoras OJ, et al. Reproducibility of gallbladder emptying scintigraphic studies. J Nucl Med. 1994;35:835-839.

14. Jacobs MP, Peterson CD. An alternative to Kinevac [letter]. J Nucl Med. 2002;43:1727. 